\title{
PENGENDALIAN DAYA HEATER PADA FASILITAS EKSPERIMEN KANAL MENGGUNAKAN MEKANISME PWM BERBASIS LABVIEW
}

\author{
Sudarno $^{1}$, Nilna Fauzia ${ }^{2}$, Alfu Alfin Nadhifatul Ummah ${ }^{2}$ \\ ${ }^{1}$ Pusat Teknologi dan Keselamatan Reaktor Nuklir - BATAN, Gedung 80 Kawasan \\ PUSPIPTEK Serpong, Tangerang Selatan, 15310 \\ ${ }^{2}$ Institut Teknologi Sepuluh Nopember, Keputih, Sukolilo, Surabaya, 60111 \\ Email: sudarno@batan.go.id
}

\begin{abstract}
ABSTRAK
PENGENDALIAN DAYA HEATER PADA FASILITAS EKSPERIMEN KANAL MENGGUNAKAN MEKANISME PWM BERBASIS LABVIEW. Fasilitas Eksperimen Kanal (ExNal) merupakan fasilitas penelitian fenomena pada bahan bakar reaktor. Dalam pengoperasiannya, ExNal perlu dilengkapi dengan heater sebagai simulator kalor yang dihasilkan reaksi fisi bahan bakar nuklir. Untuk itu, perlu adanya suatu kontrol untuk mengendalikan daya heater sesuai kebutuhan. Tujuan dari penelitian ini yaitu mengetahui kemampuan kontrol PWM terhadap daya heater dan mengetahui pada frekuensi berapa tegangan output heater bekerja sesuai duty cycle yang diberikan. Penelitian ini menggunakan perangkat lunak pengolah grafis LabVIEW. Analisis perhitungan dilakukan berdasarkan nilai duty cycle yang terbaca pada grafik waktu terhadap tegangan dan arus. Hasil pengujian menunjukkan bahwa dari delapan frekuensi yang diuji dari $0,1 \mathrm{~Hz}$ hingga $5 \mathrm{~Hz}$, daya rata-rata heater berbanding lurus dengan duty cycle yang diberikan. Namun demikian daya heater optimal akan diperoleh pada frekuensi di atas $1 \mathrm{~Hz}$.
\end{abstract}

Kata kunci : daya heater, duty cycle, eksperimen kanal, LabVIEW, PWM.

\begin{abstract}
CONTROL OF POWER HEATER ON THE CHANNEL EXPERIMENT FACILITY USING PWM MECHANISM BASED ON LABVIEW. The Channel Experiment Facility (ExNal) is a research facility to study phenomena in the reactor fuel. During operation, ExNal needs to be equipped with a heater as a heat simulator produced by nuclear fuel fission reactions. Therefore, it is necessary to have a mean to control the power of the heater as required. The purpose of this research is to know the ability of PWM mechanism to the heater power and to find out at what frequency of heater output voltage will work according to the given duty cycle. This research uses the LabVIEW graphics processing software. The calculation analysis is based on the duty cycle value that is read on the time graph of electrical voltage and current. The test results show that from the eight frequencies tested from $0.1 \mathrm{~Hz}$ to $5 \mathrm{~Hz}$, the average power of the heater is linearly proportional to the duty cycle input. Moreover, the optimal heater power will be obtained at frequencies above $1 \mathrm{~Hz}$.
\end{abstract}

Keywords : Heater Power, Duty Cycle, Cannel Experiment, LabVIEW, PWM. 
PENDAHULUAN

Reaktor TRIGA di Bandung telah memberikan kontribusi besar bagi perkembangan iptek nuklir di Indonesia. Hingga saat ini, reaktor tersebut masih beroperasi dengan baik. Namun demikian, persoalan yang muncul sejak beberapa tahun lalu adalah bahwa pabrik yang memproduksi bahan bakar untuk reaktor TRIGA sudah memutuskan untuk berhenti beroperasi [1] Hal ini perlu diantisipasi oleh semua operator reaktor TRIGA di dunia, termasuk BATAN.

BATAN telah menyusun Rencana Strategis untuk menjamin kelangsungan operasi reaktor TRIGA Bandung, diantaranya adalah dengan melakukan konversi bahan bakar TRIGA menjadi bahan bakar jenis pelat [1].

Dibandingkan bahan bakar jenis silinder, bahan bakar jenis pelat lebih sensitif terhadap vibriasi. Dalam teras reaktor, kecepatan aliran fluida pendingin elemen bahan bakar berperan penting dalam proses pemindahan panas. Kecepatan aliran pendingin berbanding lurus terhadap jumlah panas yang dipindahkan. Namun, di sisi lain kecepatan aliran pendingin juga berpengaruh terhadap vibrasi pelat bahan bakar. Vibrasi akan berdampak pada penurunan ketahanan mekanik elemen bahan bakar. Jika hal ini terjadi terus menerus, maka akan memberi dampak serius terhadap keselamatan reaktor nuklir [2].
Fasilitas Eksperimen Kanal merupakan suatu fasilitas eksperimen untuk penelitian kecepatan kritis pada aliran pendingin reaktor berbahan bakar tipe plat. Kecepatan aliran sangat dipengaruhi oleh pompa sirkulasi. Eksperimen kanal perlu dilakukan untuk dapat melihat perilaku aliran pendingin mengambil panas dari reaktor. Dalam penelitian ini dikembangkan sistem pengendalian daya heater yang bertujuan untuk mensimulasikan distribusi daya sesuai dengan posisi batang kendali. Dalam penelitian ini pengembangan dan pengujian pengendalian daya heater pada eksperimen kanal menggunakan metode kontrol Pulse Width Modulation (PWM) berbasis perangkat lunak LabVIEW.

\section{TEORI}

\section{Fasilitas Eksperimen Kanal}

Eksperimen Kanal merupakan fasilitas untuk penelitian fenomena yang terjadi pada bahan bakar reaktor. Salah fenomena yang diteliti yaitu kecepatan aliran pendingin reaktor. Kecepatan aliran pendingin sangat ditentukan oleh pompa sirkulasi. Beberapa reaktor riset di dunia menggunakan desain reaktor riset fluks tinggi yang mana memiliki kecepatan hingga $17 \mathrm{~m} / \mathrm{s}$. Sedangkan reaktor riset yang dimiliki Indonesia G.A.Siwabessy hanya memiliki kecepatan aliran pendingin $3,7 \mathrm{~m} / \mathrm{s}$. Gambar 1 menunjukkan skema eksperimen Kanal [4]. 


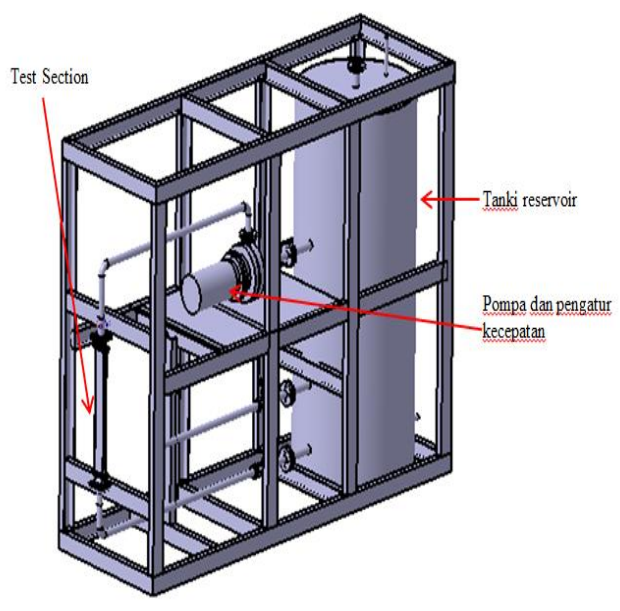

Gambar 1. Fasilitas Eksperimen Kanal (ExNal) Reaktor (courtesy : Deddy Haryanto).

Desain batang uji pada eksperimen kanal terdiri dari dua pelat dengan jarak 2,55 mm. Pada setiap pelat terdapat heater 10 buah dengan daya yang dapat dikendalikan secara terpisah. Konfigurasi ini bertujuan untuk mensimulasikan distribusi fluks neutron sesuai posisi batang kendali. Jadi, pengendalian daya ini digunakan untuk mensimulasikan gerakan batang kendali yang akan mempengaruhi distribusi daya pada elemen bakar. Aliran fluida pendingin melewati ruang antar pelat. Terdapat penyekat panas di sekeliling heater untuk menjaga agar panas tidak teradiasi ke lingkungan. Pemodelan batang uji dapat dilihat pada Gambar 2 [5].

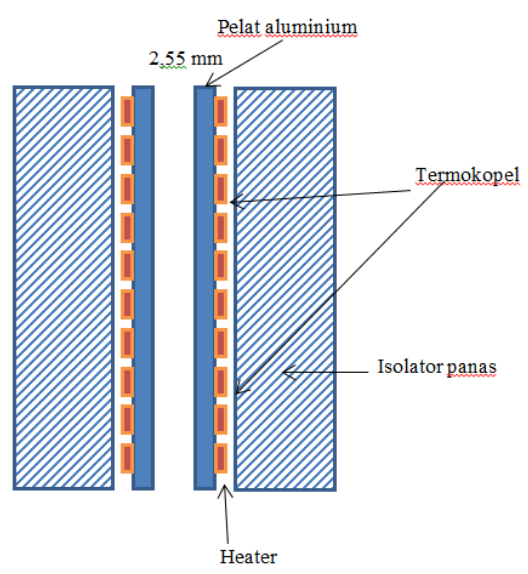

Gambar 2. Pemodelan batang uji Eksnal dengan heater

\section{LabVIEW}

LabVIEW adalah sebuah perangkat lunak untuk aplikasi instrumentasi dan akuisisi data. Program LabVIEW juga sering disebut sebagai instrumentasi virtual, karena kemampuan aplikasinya dapat menyerupai alat instrumentasi yang sebenarnya, seperti osiloskop misalnya. LabVIEW pada dasarnya menggunakan konsep bahasa pemrograman grafis yaitu dengan model blok proses dan aliran data. Terdapat 2 jendela kerja pada LabVIEW yaitu front panel dan block diagram. Front panel merupakan tampilan input dan output program untuk interaksi dengan pengguna, sedangkan block diagram berisi logika programnya $[8,9]$

\section{Modul NI 6215}

Modul National Instrument (NI) 6215 merupakan multifunctional I/O device yang berfungsi untuk akuisisi data sinyal dari sensor dan meneruskan ke komputer menggunakan program LabVIEW. Modul NI 6215 juga berfungsi sebagai modul 
kendali yang menghasilkan sinyal kendali untuk mengatur daya heater menggunakan SSR (solid state relay) [10]. Modul ini memiliki 32 kanal, terdiri dari analog I/O dan digital I/O.

\section{Pulse Width Modulation (PWM)}

Pulse Width Modulation (PWM) merupakan salah satu jenis modulasi untuk mengatur amplitudo sinyal dengan merubah lebar pulsa positif (on) dan lebar pulsa negatif (off) pada frekuensi tetap. Perbandingan lebar pulsa positif terhadap periode sinyal disebut duty cycle. Untuk membentuk sinyal PWM, dapat menggunakan modulasi dua sinyal, yaitu sinyal yang dimodulasi dan sinyal carrier yang berfungsi sebagai pengatur duty cycle.

[11]. Hubungan antara tegangan dan daya listrik yang dihasilkan oleh PWM ditampilkan dalam persamaan (1) dan (2).

$$
\begin{aligned}
& V_{P W M}=\text { D. } V_{R M S} \\
& P_{P W M}=D \cdot P_{M A X}
\end{aligned}
$$

dimana :

$$
\begin{array}{ll}
\mathrm{V}_{\mathrm{PWM}} & =\text { tegangan keluaran PWM, } \\
D & =\text { duty cycle }, \\
\mathrm{V}_{\mathrm{RMS}} & =\text { tegangan tanpa PWM, } \\
\mathrm{P}_{\mathrm{PWM}} & =\text { daya listrik dengan PWM } \\
\mathrm{P}_{\max } & =\text { daya listrik maksimal tanpa } \\
& \text { PWM. }
\end{array}
$$

\section{METODOLOGI}

Tata kerja pembuatan sistem akuisisi data dan pengendalian daya heater mengikuti tahapan-tahapan kegiatan seperti pada Gambar 3.

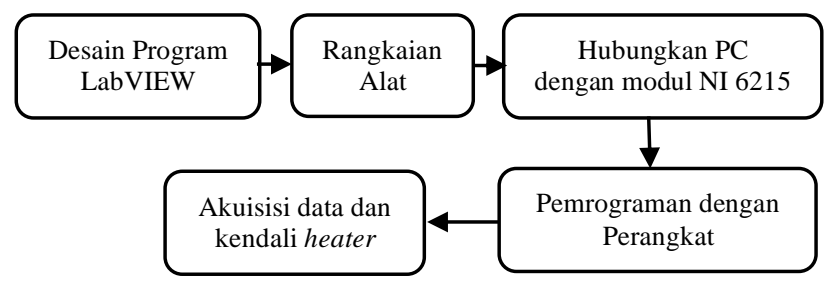

Gambar 3. Skema kerja pembuatan sistem akuisisi data dan kendali daya heater.

Adapun Peralatan yang digunakan adalah sebagai berikut

- 1 unit modul NI-USB 6215

- 1 unit heater 300 Watt

- 1 unit Solid State Relay

- 1 unit resistor $20 \mathrm{Ohm}$

- 1 unit trafo step down 3 Volt

- 1 unit klem arus, dan

- 1 unit termokopel tipe $\mathrm{K}$

Rangkaian elektronika dihubungkan dengan pinout pada NI-USB 6215. Setelah terhubung, dilakukan pemrograman antara software LabVIEW dengan hardware NIUSB 6215. Tampilan program pada jendela front panel dan block diagram LabVIEW dapat dilihat pada Gambar 4 dan 5. Akuisi data diatur agar dapat membaca tegangan, arus keluaran heater dan temperatur pada termokopel setiap 1 mili detik. Pada front panel ditampilkan nilai digital dan grafik dari setiap tegangan, arus, dan temperatur yang terbaca. Penyimpanan data dilakukan dengan menekan tombol save pada front 


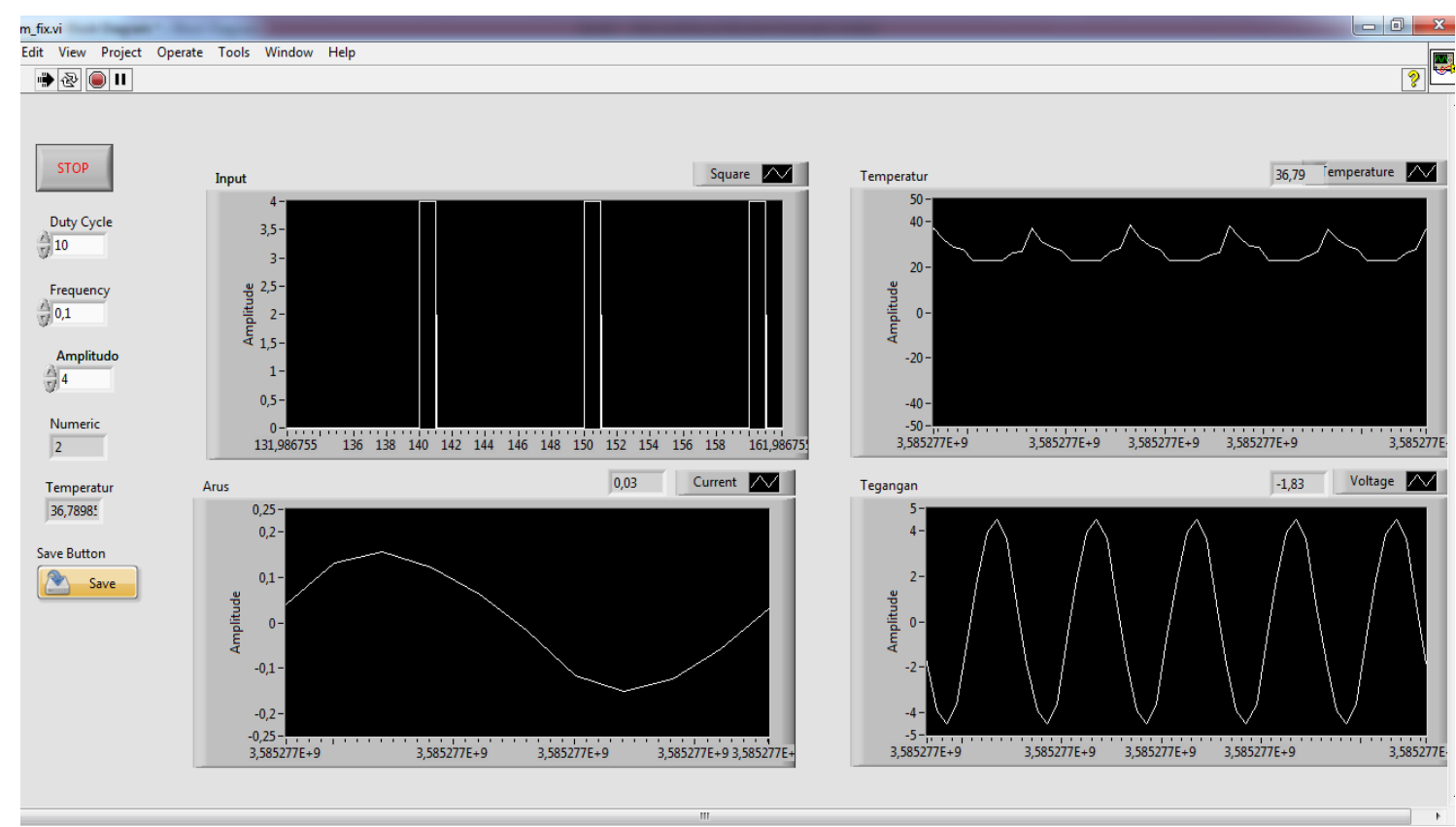

Gambar 4. Tampilan front panel saat akuisisi data kontrol daya heater.

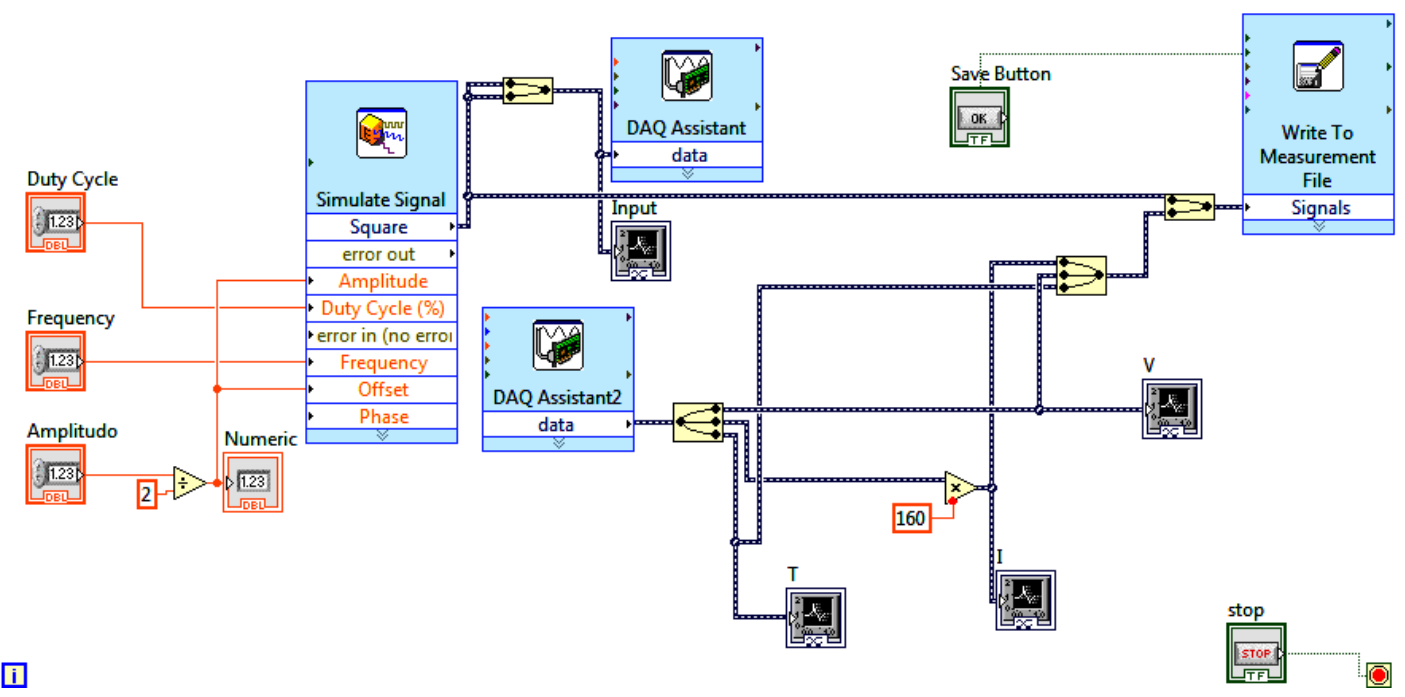

Gambar 5. Diagram blok sistem akuisisi data pada pengaturan daya heater.

panel. Data disimpan dengan format .lvm sehingga data dapat dengan mudah dianalisa HASIL DAN PEMBAHASAN dengan software Microsoft Excel.

Proses pengendalian daya heater diawali dengan menentukan frekuensi dan duty cycle. Diagram alir program akuisisi data dan pengaturan daya heater ditunjukkan pada Gambar 6.

Pengendalian daya dilakukan dengan mengatur nilai duty cycle dari sinyal yang masuk pada heater. Pengaturan ini dilakukan dengan perangkat lunak LabVIEW dan dilengkapi perangkat keras National Instrument (NI) jenis multifunctional I/O NIUSB 6215. Adapun pinout yang digunakan untuk analog output adalah pin 12 sebagai 
Analog Output 0 (AO0), pin 13 sebagai Analog Output 1 (AO1) dan pin 14 sebagai Analog Ground. Pin ini digunakan untuk mengirim sinyal PWM dari PC menuju SSR (solid state relay). Adapun analog input yang digunakan adalah pin 17, 19, 21 dan 23. Pin 17 adalah pin Analog Input 1 (AI1) sebagai penerima tegangan yang terukur pada heater. Pin 19 adalah pin Analog Input 2 (AI2) sebagai penerima arus yang terukur pada heater. Pin 21 dan 23 sebagai pin AI3 dan AI sense untuk menerima akuisisi data suhu dari pengukuran termokopel.

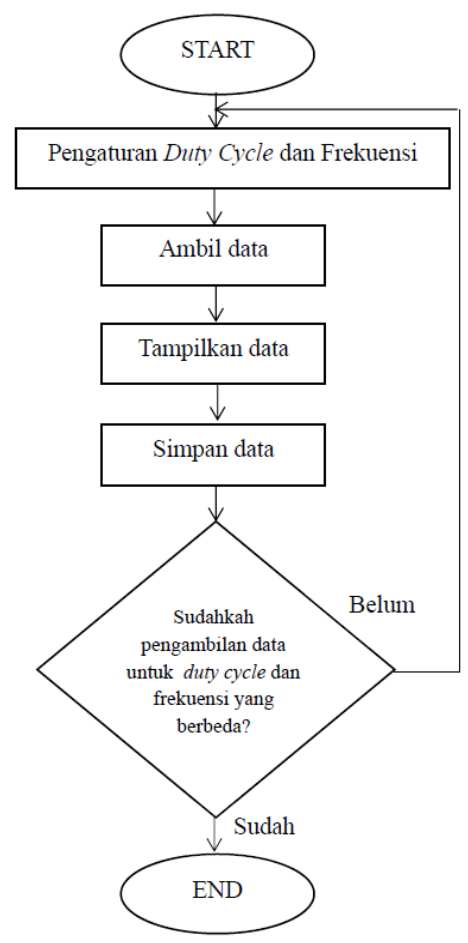

Gambar 6. Diagram alir program akuisisi data dan pengaturan daya heater.

Proses akuisisi data dimulai dengan pengaturan duty cycle dan frekuensi pada program, seperti yang dapat dilihat pada Gambar 4 yang menunjukkan grafik input duty cycle, tegangan dan arus yang pada heater serta suhu yang terukur pada termokopel. Komputer akan mengirimkan sinyal digital menuju NI-USB 6215 yang selanjutnya akan diteruskan menuju SSR. Kemudian relai akan bekerja sesuai dengan kontak switch SSR untuk mengatur besarnya energi listrik rata-rata yang disuplai ke heater.

Untuk mengetahui daya listrik yang disuplai ke heater, maka dilakukan pengukuran arus dan tegangan heater. Pengukuran tegangan pada heater dilakukan dengan trafo stepdown, sehingga pengukuran tegangan dapat direkam dengan NI-USB 6215 pada inteval -10 Volt sd. 10 Volt. Sedangkan pengukuran arus dilakukan dengan metode induktif menggunakan klem arus.

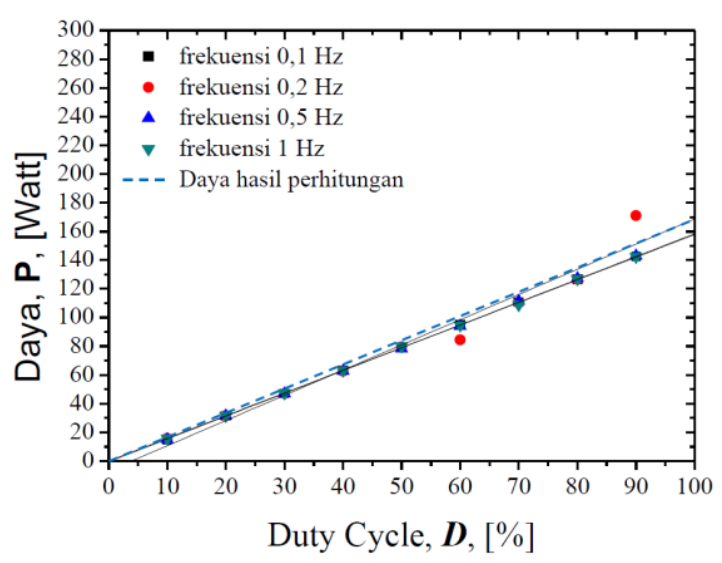

Gambar 7.(a) Pengaruh duty cycle terhadap daya heater pada frekuensi $0,1 \mathrm{sd} .1 \mathrm{~Hz}$. 


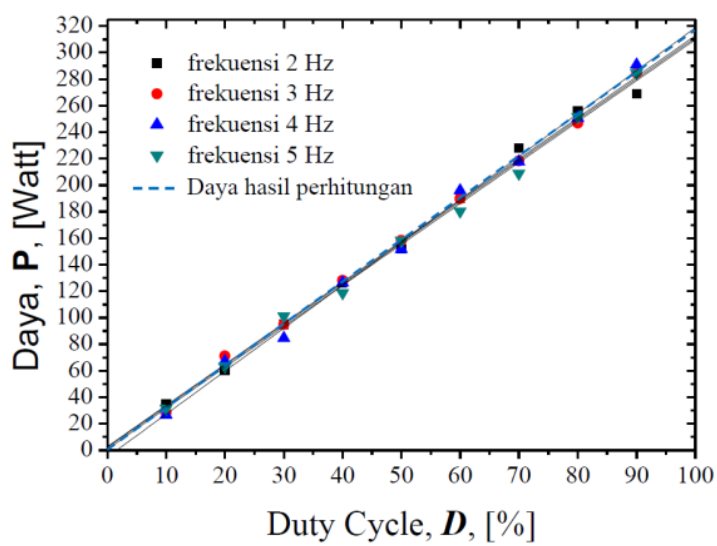

Gambar 7.(b) Pengaruh duty cycle terhadap daya heater pada frekuensi $2 \mathrm{sd} .5 \mathrm{~Hz}$

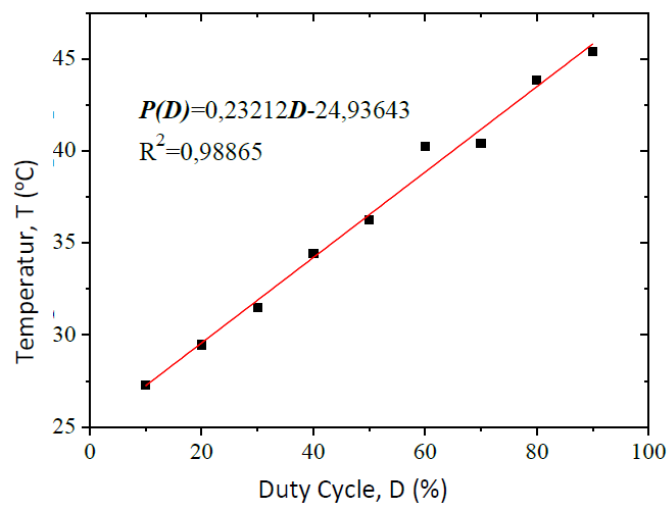

Gambar 8. Pengaruh duty cycle terhadap temperatur air.

Grafik pengaruh duty cycle terhadap daya rata-rata dengan parameter frekuensi sinyal PWM yang berbeda-beda dapat dilihat pada Gambar 7. Pada frekuensi $\leq 1$ $\mathrm{Hz}$, nilai pengukuran daya heater lebih kecil dari nilai perhitungan dengan nilai selisih daya maksimal 5,9\%. Pada frekuensi $>1 \mathrm{~Hz}$, nilai pengukuran daya heater lebih sesuai dengan perhitungan, dengan nilai selisih daya maksimal 1,6\%.

Media dalam percobaan ini adalah air. Heater diletakkan di dalam air sehingga temperatur air akan mengalami peningkatan seiring bertambahnya nilai daya rata-rata oleh heater. Dari eksperimen diperoleh pula bahwa temperatur air juga berbanding lurus dengan duty cycle seperti yang terlihat pada Gambar 8 .

Hasil yang diperoleh dari eksperimen adalah sesuai dengan persamaan (2) dimana daya heater rata-rata berbanding lurus dengan duty cycle. Dengan demikian metode PWM cocok untuk dijadikan metode pendalian daya heater. Berdasarkan variasi frekuensi sinyal PWM yang telah dilakukan diketahui bahwa untuk frekuensi PWM terlalu rendah (f $<1 \mathrm{~Hz}$ ) menghasilkan penurunan daya hingga $5,9 \%$ dari nilai perhitungan. Dengan demikian untuk pengendalian heater disarankan menggunakan frekuensi sinyal PWM diatas $1 \mathrm{~Hz}$ untuk mendapatkan penurunan daya heater kurang dari $1,6 \%$ terhadap nilai perhitungan.

\section{KESIMPULAN}

Berdasarkan eksperimen dan pengolahan data diketahui bahwa nilai daya heater berbanding lurus terhadap duty cycle sinyal PWM, sehingga metode PWM cocok dijadikan metode pengendalian daya heater. Pada frekuensi PWM $\leq 1 \mathrm{~Hz}$, daya heater yang terukur mengalami penurunan daya hingga $5,9 \%$. Nilai daya heater yang optimal diperoleh pada frekuensi PWM $>1 \mathrm{~Hz}$, untuk mendapatkan penurunan daya heater kurang dari 1,6\% dari perhitungan. 
UCAPAN TERIMA KASIH

Penulis mengucapkan terima kasih kepada pimpinan manajemen PTKRNBATAN yang memfasilitasi penelitian ini.

\section{DAFTAR PUSATAKA}

[1] H. SUWARNO, Development of TRIGA Fuel Fabrication by Powder Technique. Atom Indonesia Vol. 40 No. 3 (2014) 113.

[2] PTNBR-BATAN. Strategic Plan: Bandung TRIGA Research Reactor, 2013.

[3] KISWANTA, Perancangan Modifikasi Pompa Pendingin pada Fasilitas Eksperimen Kanal. Sigma Epsilon, 2014, Vol 18:2.

[4] MUHAMMAD SUBEKTI, ENDIAH PUJI HASTUTI, DEDI HERIYANTO, Desain Alat Eksperimen Kanal (ExNal) untuk Mengukur Kecepatan Pendingin Reaktor Riset Inovatif" Prosiding Pertemuan dan Presentasil Ilmiah Penelitian Dasar Ilmu Pengetahuan dan Teknologi Nuklir, 2014, Hal. 3641.

[5] ANTÔNIO CARLOS LOPES DA COSTA ET AL, AN Electrical Simulator of A Nuclear Fuel Rod Cooled by Nucleate Boiling, ECI International Conference on Boiling
Heat Transfer Florianópolis-SCBrazil, 3-7 May 2009.

[6] KAMINAGA M., Thermal hydraulics Design of JRR-3M, The 38th, 39th and 40th Instructur Training Program - Course of Reactor Engineering I, II \& III, JAEA, Tokai, 2010.

[7] DAXIN GONG, ET AL., Heat Transfer Calculation on Plate-Type Fuel Assembly of High Flux Research Reacto., Science and Technology of Nuclear Installations, Hindawi Publishing Corporation, Volume 2015.

[8] KUSSIGIT SANTOSA, Rancang Bangun Sistem Otomatisasi Katup Pada Untai Uji Beta Menggunakan Perangkat Lunak LabVIEW, Sigma Epsilon, ISSN 0853-9103, Vol 18, No 3-4 Agustus-September 2014.

[9] AGUS NUR RACHMAN, Pengembangan Sistem Instrumentasi Thermobath dan Akuisisi Data Termokopel Tipe K, Sigma Epsilon, ISSN 0853-9103, Vol 20, No. 1 Februari 2016.

[10] NATIONAL INSTRUMENTS, Operating Instructions and Specifications NI 9215. 2017.

[11] JIAN SUN, Dynamics and Control of Switched Electronic Systems Advanced Perspectives for Modeling, Simulation and Control of Power Converters. London: Springer-Verlag, 2012. 